\title{
Ni calco ni copia. Antología de la filosofía peruana contemporánea de Rubén Quiroz Ávila
}

\section{Marco León Felipe Barboza Tello ${ }^{1}$}

Universidad Nacional Mayor de San Marcos. Lima, Perú

marco.barboza@unmsm.edu.pe

ORCID: 0000-0002-5983-3205

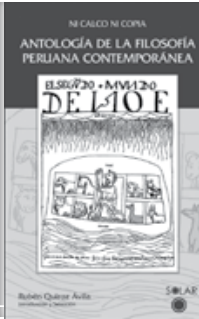

Citar como: Barboza, M. (2021). Ni calco ni copia. Antología de la filosofía peruana contemporánea de Rubén Quiroz Ávila. Desde el Sur, 13(3), e0037.

Es una intención razonada del antologador la de mostrar «las tensiones conceptuales y las líneas de acción reflexiva de una comunidad intelectual» como la peruana, ahondando en los debates filosóficos que han marcado tanto la agenda intelectual como nuestro mapa reflexivo, lo que constituye un auténtico "archivo de discusión filosófica contemporánea» (pp. 5-6). Esa es la premisa teórica de la selección de textos Ni calco ni copia. Antología de la filosofía peruana contemporánea (Solar, 2019), que pasaremos a reseñar a continuación.

La antología inicia con el artículo intitulado «Universalismo y latinoamericanismo» de Francisco Miró Quesada, en el cual el autor relata, a la manera de un observador entropado (arguediano), su propia experiencia como actor protagónico del filosofar latinoamericano durante la segunda mitad del siglo $X X$, proceso que él concibe como «el enfrentamiento de dos concepciones de lo que debe ser la filosofía auténtica en América Latina» (pp. 23-24). Para este autor el del universalista es un filosofar en clave de intérprete que desarrolla el canon occidental, en tanto el latinoamericanista solo admite en la realidad propia y próxima la fuente de su filosofar. De la década de 1940 en adelante refiere célebres encuentros, debates y apuestas en torno a esa cuestión. Leopoldo Zea y él mismo polemizando en 1946, el brillo auténtico de Bunge en 1963 en la cita mexicana de la FISP2 , la conciencia revalorizadora y comprometida del propio Miró Quesada en torno al sesquicentenario republicano, la Declaración de

\footnotetext{
1 Abogado de la Universidad Nacional de Trujillo. Doctorando en Filosofía por la Universidad Nacional Mayor de San Marcos y máster en Gestión y Dirección de Sistemas de Seguridad Social por la Universidad de Alcalá. Es Visiting Research Fellow in the Wolfson Institute of Population Health, Queen Mary University of London. Artículos suyos han sido publicados en Health Policy and Planning, BMJ Global Health, Ethics and International Affairs y Documentos de Trabajo (IELAT).

2 Federación Internacional de Sociedades Filosóficas (por sus siglas en francés).
} 
Morelia conjugando el pensamiento liberacionista y la mirada analítica, son solo algunos de ellos. Entendiendo que la corriente latinoamericanista se consolida principalmente en torno a la filosofía de la liberación, Miró Quesada realiza un diagnóstico que él mismo califica como «un proceder de manera pragmática» y de optimismo tecnológico que busca actualizar la aspiración de la «meta última de la filosofía de la liberación [:] la sociedad sin clases» (p. 40). Tomando en cuenta la fecha del artículo (1998) y la proximidad del giro filosófico pragmatista, ello no es casual en absoluto. Por el frente analítico (léase universalista) releva las contribuciones de Bunge, Newton da Costa, Villoro y Moulines desde una impronta recurrente: «la humanización del mundo, se [puede] hacer utilizando los métodos rigurosos y simples de la lógica formal» (p. 34). Miró Quesada postula la progresiva autofundamentación articuladora como base para el devenir de la producción filosófica latinoamericana. Ello, y la incesante producción -con variantes - de filósofos «políticos» y «analíticos» en la actualidad continental y global, parecen dos sintéticos y persistentes asertos.

«El comienzo del filosofar» de Augusto Salazar Bondy (1967) es un convite, una propuesta iniciática de lecturas para filósofos principiantes. De Platón a Kant, de Romero a C. E. M. Joad, o de Zea a Wahl, pasando por Gaos, Russell, Simmel, Abbagnano, Jolivet o I. Brugger, se explicitan con detalle manuales, ensayos, antologías, diccionarios, vocabularios o compendios bibliográficos. Para Salazar, el vínculo explícito de corrientes filosóficas en formato de introducción o de principios se encuentra en Le Senne (metafísica espiritualista), Marías (vitalismo orteguiano), Maritain (neoescolástica), Jaspers (existencialismo), Politzer (marxismo), Hospers (filosofía analítica). Se hace una mención especial a ¿Qué es filosofía? de Ortega y Gasset, Esencia de la filosofía de Max Scheler, Teoría de la concepción del mundo de Dilthey, así como a La filosofía en Iberoamérica de Wagner de Reyna o el «¿Cómo se debe leer a Kant?» de Miró Quesada. Salazar enfatiza dos cuestiones en el filosofar: la admiración como la filosofía primera, triple conjunción de «esfuerzo de conversión espiritual, [l]argo ejercicio de liberación de la mente [y] aprendizaje» (p. 53), y la tesitura dialógica del ejercicio filosófico, que ostenta la doble condición de estar inserto en una larga tradición reflexiva y ser «un proceso abierto de asimilación, provocación y transmisión de inquietudes, dudas y convicciones acerca de los problemas de la existencia» (p. 50). La ingenuidad, el pensar «naturalmente» o la relación cósmica en estado puro se asumen como antitéticas de la elaboración conceptual o del lenguaje científico técnico, bases consustanciales del pensar filosófico. Cincuenta años después de la reflexión salazariana, la intersección original de poetas, sacerdotes, chamanes, médicos y filósofos se va acreditando con cada vez más fuerza en 
campos tan diversos como la filosofía ambiental, la filosofía de la ciencia o la historia de la filosofía. Si Salazar viviera, de seguro daría cuenta también de esta democratización mítica y bacterial de los orígenes del filosofar, una auténtica irreverencia del pensar.

Un grito de batalla parece recorrer el «Prólogo» de Repensando la tradición nacional de David Sobrevilla (1989) y es el siguiente: repensémonos en el filosofar. Según Sobrevilla, dar cuenta de una tradición de la filosofía peruana tiene algunas particularidades, las que describimos a continuación a manera de preguntas y respuestas. ¿Su selección? Iberico, Wagner de Reyna, Peñaloza, Salazar Bondy, Miró Quesada C., Guardia Mayorga. ¿Su intención? Reivindicar la filosofía peruana, «reconociendo su propia tradición nacional, sus posibilidades y los requerimientos concretos de la realidad de la parte» (p. 71). ¿Sus criterios? Coherencia, fundamentación, pruebas aportadas, así como la contraposición del planteo filosófico acerca de determinado tema, la fidelidad programática y su viabilidad. ¿Su consideración final general? «La relación del pensamiento de cada autor con la tradición de la filosofía occidental, con la tradición y filosofía en el Perú, y la validez, realización y posibilidades de cada proyecto filosófico» (pp. 76-77). Pensando en las nuevas generaciones filosóficas peruanas traigo a colación la frase de Francisco Miró Quesada, «[son] los dos altos fines que persigue todo filósofo auténtico: decir primero cómo es, y luego, cómo deber ser el mundo» ${ }^{3}$.

Edgar Montiel (2010) es el siguiente autor; de él se incorpora en el recuento antológico «El Inca Garcilaso y la independencia de las Américas». En dicha contribución Montiel analiza los Comentarios reales de los incas de Garcilaso, y lo ubica en tres ámbitos: «en la construcción del derecho natural, en la literatura de la llustración y [e]n las visiones filosóficas y utopistas» (p. 82). La edición de 1744 de Le Jardin du Roy, la obra de teatro A/zire de Voltaire, el Código de la naturaleza de Morelly, la teoría política —en particular, el estado natural- de Locke, La nueva Atlántida de Bacon, son todas expresiones que comprenden filosofía, arte, historia y política que hallan su orto o impulso fundamental en los Comentarios reales, para el caso europeo. Así también, el fervor americano expresado en el «nacionalismo inca» de Túpac Amaru, el independentismo criollo y la creación de sociedades patrióticas, la búsqueda de «la historia de las antiguas culturas americanas [como] factor de orgullo y legitimación», se correspondían con la intención del Inca Garcilaso, quien escribió de forma señera en la

3 Discurso leído en el homenaje que la Sociedad Peruana de Filosofía rindió a Augusto Salazar Bondy el 3 de abril de 1974 en la sede central del Instituto Nacional de Cultura (Miró Quesada, 1974, p. 134). 
dedicatoria de los Comentarios reales: «A los indios, mestizos y criollos de los Reinos y provincias del grande y riquísimo Imperio del Perú, el Inca Garcilaso de la Vega, su hermano, compatriota y paisano» (pp. 97, 93).

«En torno a la identidad» de María Luisa Rivara es una publicación que inaugura el nuevo siglo y versa sobre lo idéntico real ontológico, expresado en «la existencia real de una pluralidad de culturas, etnias y lenguas que conviven y persisten paralelamente como resultado de un proceso tempo-espacial que [h] contribuido y contribuye a construir el ser nacional» (p. 104). Un concepto central de este artículo es que la creación en pluralidad, en clave de aceptación y convivencia, sobre la base de culturas, lenguas y etnias diversas explica el curso de la historia nacional. La coexistencia pluricultural es un continuum que permea nuestra identidad desde la época del incanato hasta los modelos culturales más recientes, capitalistas, socialistas o neoliberales. Finalmente, Rivara postula una «teoría teleológica [prospectiva, que] termine con los [m]odelos que impuestos, adoptados o adaptados, no han podido actuar sino defectivamente sobre esta realidad» (pp. 109-110).

«El principio interculturalidad y la filosofía de la plenitud» de José lgnacio López Soria pasa revista más recientemente a rasgos centrales de la cultura occidental, concretamente su «tradición dialógica» que se condice con la carencia de un fundamento de universalidad para la humana heterogeneidad, la copertenencia en el lenguaje del diálogo y la interculturalidad, y la condición utópica contemporánea, que no es otra que el «[cultivo] de diferencias abiertas a la convivencia y construir convivencias cultivadoras de diferencias». Tres tipos de actitudes frente a los consensos en torno al crecimiento y desarrollo son necesarias, según este autor: la vigilancia, que implica un mirar atento de agendas y compromisos y también debiera interpelar el «crecimientismo»; la crítica en doble perspectiva del desarrollo: terapéutica respecto de sus patologías y deconstructiva de sus fundamentos; y la proposición de horizontes de significación y de vida buena. A modo de conclusión, lo que instala la reflexión de López Soria - aunque, como el mismo señala, requerirá desarrollos ulterioreses el «pensar la vida humana en términos de plenitud y no de desarrollo [, h]acer la experiencia de la verdad, la virtud, la belleza y la vida buena como seres con el mundo y con otros» (pp. 142, 144).

El pragmatismo es el gran protagonista de los artículos de José Carlos Ballón (1994) «Ética, modernidad y autoritarismo: ¿VIGILAR Y CASTIGAR?, y Teresa Arrieta (2016) «Ética ambiental: del dominio al respeto de la naturaleza». Aun cuando entre uno y otro median más de dos décadas de diferencia, se advierten tópicos concurrentes cuando se argumenta sobre «la pragmática que denotan nuestros discursos y reglas morales», la 
postulación de «hipotéticos universales pragmáticos que nos permitan una teoría ética general», las relaciones contextualistas, el «humanismo pragmático e instrumental», o el principio de solidaridad cooperativa asumido como sinónimo de justicia (Rawls) ${ }^{4}$. Así, entre el problema de «la ausencia de una ética del trabajo como medida social de la distribución e intercambio» postulado por Ballón (p. 156) y la asunción de Arrieta de la propuesta de Norton «de una nueva filosofía ambiental basada en el pragmatismo, que apoya la aproximación de aprender-haciendo, para lograr una vida sostenible» (p. 196), se advierte la justificación contextualista de Rainer Forst ${ }^{5}$ y las aseveraciones de Richard Sennett sobre la «intención del pragmatismo e[n] enfatizar la indagación ética durante el proceso de trabajo [, y e]l orgullo por el trabajo propio [que] anida en el corazón de la artesanía como recompensa de la habilidad y el compromiso» (2010, pp. $361,363)$. Con lo expuesto, la influencia del pragmatismo en la actualidad de la filosofía peruana pareciera una agenda de investigación emergente.

«Latinoamérica: el reto de las redefiniciones» de Juan Abugattás (1990) y «La filosofía entre nosotros: cinco siglos de filosofía en el Perú» de Augusto Castro (2009) son dos posturas comprometidas con la autenticidad del pensar filosófico peruano, superadoras de la ajenidad, el desaliento y la fragmentación. Abugattás considera indispensable la necesaria asunción latinoamericana de una «liberación de [la] capacidad de soñar e imaginar [c]on autonomía y libertad» sostenida en el fortalecimiento institucional de la política «capaz de exigir [e]l derecho de vivir para sí» (pp. 213, 215). Castro, en tanto, signa un recorrido histórico de la filosofía peruana, con énfasis en períodos determinados; a saber: el siglo XVII colonial, el liberalismo peruano en torno a la independencia, el positivismo no alejado de posturas religiosas y estéticas, el espiritualismo con referencias a Deústua, García Calderón, Iberico y Zulen, y finalmente, la liberación y esperanza en Salazar Bondy y Noé Zevallos. Castro define como un elemento central de su indagación histórica el «integrar en un haz la mirada universal y a propia» (p. 219).

Pablo Quintanilla (2004) es el autor del siguiente texto antologado, el mismo que se intitula: «Interpretando al otro: comunicación, racionalidad y relativismo». La determinación de creencias, deseos y acciones en el marco de situaciones comunicativas, concebir el conocimiento como participación constitutiva y transformadora de la realidad, articular una teoría de la simulación al principio de caridad davidsoniano, y postular una teoría de la cooperación interpretativa (creación compartida por

4 Ver pp. 159, 184, 188, 194.

5 De mucho impacto en el campo de los derechos humanos y el medioambiente. 
intérprete y agente) son puntos fuertes en la argumentación del filósofo. La racionalidad para Quintanilla implica «la posibilidad de crear un espacio de interpretación intencional común, lo que dará lugar a una forma de vida compartida [,] a una fusión de horizontes» (p. 236). Finalmente, el filósofo distingue entre un etnocentrismo con complejo de superioridad epistemológica o axiológica, y un etnocentrismo inevitable y deseable, por el cual el sujeto se permite «ver a los otros como semejantes con los que tiene lazos de solidaridad y responsabilidad morales» (p. 257). Es ineludible ver en la reflexión de Quintanilla una acumulación de la teoría de la justicia (cooperativa) rawlsiana, la conciencia moral y acción comunicativa habermasiana, «Objetividad, relativismo y verdad» de Richard Rorty, así como, los efectos transicionales de los sucesivos giros lingüísticos y hermenéuticos. De fecha mucho más reciente, se ha acreditado enfáticamente que la comunicación «es sensorial, incluyendo lo auditivo, lo visual, lo cinestésico, lo táctil, lo olfativo, lo gustativo y lo interoceptivo, y puede involucrar a humanos, no humanos, plantas y/o máquinas» (Universidad de Oregon, 2021). He ahí otra agenda de investigación emergente para el pensar filosófico peruano.

La exploración en torno al pensar filosófico de los antiguos peruanos efectuada por Víctor Mazzi (2012) en «Kay, pacha, yachay. La reflexión y el saber en el Tawantinsuyo» y Zenón Depaz (2014) en «Experiencia cósmica y dinámica social en el Manuscrito de Huarochirí» es amplia, sugerente y rotunda. Haciendo un recuento de lingüística histórica del quechua y el aimara, en ambos textos se efectúan interesantes hallazgos: «hamut'aq es traducido [c]omo «sabio, prudente, cuerdo» [, «]el que enseña cosas altas y muy bien» (p. 271), trátase del filósofo, representado por los más ancianos. Otro tanto ocurre con la decisión tomada ante la ruina del santuario de Pariaqaqa: Haku chiqirisuntaq wawqi («vamos, dispersémonos, hermanos»), que «anunciaría simbólicamente una estrategia de vida de alcance civilizatorio, consistente en volver al germen, a la dispersión y la noche de la semilla, cuando un orden social se muestra insuficiente para albergar la diversidad que contiene, para luego nuevamente florecer [como] una afirmación de la vida y el orden que lo sostiene» (p. 305). Deidades, cosmogonías, rituales y comprensión de mundo puestas en diálogo, afloran con términos como kay (existencia), pacha (naturaleza, universo), yachay (conocimiento basado en la razón y el cambio del mismo) (p. 283). El Manuscrito de Huarochirí, escrito entre fines del siglo XVI e inicios del siglo XVII daría «cuenta de un mundo en el que la experiencia humana tiene raigambre cósmica y la vida se concibe como el fluir de una energía vital (kama) que discurre por el cosmos entero (pacha), poblado de seres que constituyen comunidades (ayllu) vinculadas entre sí en relaciones 
de crianza mutua, siguiendo determinadas pautas rituales que, a su vez, constituyen la matriz simbólica del orden y la normatividad» (p. 307). Para Depaz, este es un fondo mítico capaz de soportar políticamente la rearticulación del espacio andino y la patria grande latinoamericana en clave contemporánea. La concreción de dicha apuesta no obsta que dicho conocimiento se inscriba en el horizonte de El chamanismo de Mircea Eliade, de la centralidad de la religión en las ciudades arcaicas de Mumford, de la detallada descripción del salvaje europeo de Bartra o de las relaciones entre el exorcista y el médico babilónicos en el curso de la era axial explicitadas por Geller (2010). Se abre así una interesantísima línea de investigación sobre el pensamiento cósmico universalizado y dialógico de los saberes ancestrales, en momentos que la historia de la filosofía, la historia de las religiones y la historia de las emociones están comenzando a sostener un pas de trois horizontal y elucidante ${ }^{6,7}$.

A manera de colofón es necesario considerar que una antología para una filosofía como la peruana, con valor y fisonomía y propias, pero cuyo autorreconocimiento y revalorización es todavía un proceso en ciernes, será siempre subjetiva, parcial e inacabada. Aun con ello, trátase de una labor necesaria e impostergable, como lo es el desarrollo de las ideas en un promisorio mundo patria en el que confluyen, de manera proteica y alquímica, la melancolía del pensar y el pathos ancestral y milenario, bases ineludibles de todo filosofar auténtico.

6 En el mismo orden de ideas/creencias, Jürgen Habermas ha señalado recientemente: «Como filósofo me interesa la cuestión de lo que podemos aprender del discurso sobre la creencia y el conocimiento [,] lo que me interesa es el proceso de traducción conceptual de los contenidos centrales de la tradición religiosa» (Schwering, 2020).

7 Se recomienda revisar Argumanis (2015). 


\section{REFERENCIAS BIBLIOGRÁFICAS}

Argumanis, E. W. L. (2015). El progreso providencial. Análisis e interpretación conceptual de la filosofía política desarrollada en la Facultad de Letras de San Marcos a fines del siglo XIX (1869-1909). Desde el Sur, 7(2), 293-316.

Geller, M. J. (2010). Ancient Babylonian medicine. Theory and practice. John Wiley and Sons.

Miró Quesada Cantuarias, F. (1974). Augusto Salazar Bondy: biografía filosófica. Textual, 9, pp. 131-134.

Miró Quesada Cantuarias, F. (1998). Universalismo y latinoamericanismo. Isegoría, (19), 61-77. https://isegoria.revistas.csic.es/index.php/isegoria/ article/view/131/131

Schwering, M. (2020). Entrevista con Jürgen Habermas in «Kölner Stadt-Anzeiger». (Completa, 3 de abril de 2020). https://filoelearning. com/2020/04/05/entrevista-con-habermas-in-kolner-stadt-anzeiger3-de-abril-de-2020/

Sennett, R. (2010). El artesano. Anagrama, pp. 361, 363.

Universidad de Oregon. (2021). What is communication? https://blogs.uoregon.edu/whatiscommunication/ 